\title{
Colony Development and Density-Dependent Processes in Breeding Grey Herons
}

\author{
Takeshi Shirai \\ Department of Biology, Tokyo Metropolitan University, Minamiosawa 1-1, Hachioji, Tokyo 192-0397, Japan \\ Correspondence should be addressed to Takeshi Shirai; ardea@k00.itscom.net
}

Received 14 December 2012; Accepted 8 January 2013

Academic Editor: Eugene S. Morton

Copyright (C) 2013 Takeshi Shirai. This is an open access article distributed under the Creative Commons Attribution License, which permits unrestricted use, distribution, and reproduction in any medium, provided the original work is properly cited.

\begin{abstract}
The density-dependent processes that limit the colony size of colonially breeding birds such as herons and egrets remain unclear, because it is difficult to monitor colonies from the first year of their establishment, and the most previous studies have considered mixed-species colonies. In the present study, single-species colonies of the Grey Heron (Ardea cinerea) were observed from the first year of their establishment for 16 years in suburban Tokyo. Colony size increased after establishment, illustrating a saturation curve. The breeding duration (days from nest building to fledging by a pair) increased, but the number of fledglings per nest decreased, with colony size. The reproductive season in each year began earlier, and there was greater variation in the timing of individual breeding when the colony size was larger. The prolonged duration until nestling feeding by early breeders of the colony suggests that herons at the beginning of the new breeding season exist in an unsteady state with one another, likely owing to interactions with immigrant individuals. Such density-dependent interference may affect reproductive success and limit the colony size of Grey Herons.
\end{abstract}

\section{Introduction}

Wading birds such as herons and egrets nest in colonies in relatively limited areas and at high density, often reaching hundreds or thousands of pairs [1]. Herons and egrets are usually quite large birds, and the dynamics of their population attract much attention, as estimating the number of breeding pairs is easier in colony-breeding birds than in noncolony breeders. Population fluctuations may be caused by densitydependent and density-independent processes, although the two are not mutually exclusive.

Density dependence is a negative feedback between population growth rate and population density [2]. In a White Heron (Egretta alba) colony, the mean number of fledglings per nest decreased as the number of nests in the colony increased, suggesting a density-dependent response [3]. The first egg-laying date was delayed when colony size was large in a Purple Heron (Ardea purpurea) colony [4]. However, little unequivocal evidence shows that densitydependent factors regulate population fluctuations of wading birds, because intraspecific competition for breeding and colony sites appears to be unimportant in determining the reproductive success or survival in most species $[5,6]$. Instead of tracking yearly changes in a single colony, intercolonial comparisons in the same year are useful to detect densitydependent processes, and such comparisons have been conducted in herons and egrets. Results have shown that final breeding success is negatively correlated with colony size in Grey Herons (Ardea cinerea) in Belgium [7] and Great Blue Herons (Ardea herodias) in Canada [8]. However, in Grey Herons in northern Poland, breeding success increases with colony size [9]. Different conditions within each colony habitat, such as the distance to feeding sites and predation risks, may cause opposing results for the relationship between colony size and breeding success.

Density-independent factors have also been suggested to affect the population fluctuations of herons and egrets. Unpredictable factors such as cold weather, high winds, disease, food shortage, and human impacts can explain reduced breeding success and increased mortality in some regions without invoking density-dependent mechanisms 
$[5,10,11]$. In particular, winter temperature is known to affect populations of herons and egrets via increased mortality [1215]. Winter temperature also affects the onset of the breeding season in Grey Herons [16-19].

Short-term studies are suboptimal for detecting the effects of density on the dynamics of wading bird populations, because birds are long-lived and breed annually [1]. Even in the several long-term studies conducted to date, census data were not recorded beginning with colony establishment but with mature colonies (e.g., [10-12, 20-23]). The tendency of wading birds to form mixed-species groups has posed another difficulty for detecting density-dependent processes in colony size regulation; in these cases, both intra- and interspecific interactions affect individual behavior and survival $[24,25]$.

In the present study, to simplify the factors affecting density-dependent processes of colony breeders, a singlespecies colony of Grey Herons was selected and monitored for 16 years beginning at its establishment. I investigated the long-term population fluctuation patterns in this colony and examined density-dependent phenomena based on individual breeding behavior and reproductive successes in the colony. With respect to density-independent factors, I examined how winter temperatures affect colony size and individual breeding behavior.

\section{Methods}

2.1. Study Animal and Study Sites. The breeding range of Grey Herons covers most of the Old World south of the Arctic Circle, including Europe, Africa, Asia, and the East Indies islands to Wallace's Line [1]. After the breeding season, generally when the young can fly, they disperse in all directions [1]. Therefore, the nonbreeding range expands outside of the breeding range. These birds are sedentary and widely distributed in Japan [26]. They feed on a variety of aquatic animals such as fish, amphibians, crustaceans, insects, and worms [1]. Feeding sites include ponds, lakes, rivers, marshes, and seashores (shallow tidal bays), and they often use artificial water environments such as rice fields, fish farms, parks, and dams [27].

In 1996, a breeding colony of Grey Herons became established at a hillside at Renkoji in suburban Tokyo $\left(35^{\circ} 39^{\prime} \mathrm{N}\right.$, $139^{\circ} 28^{\prime} \mathrm{E}$ ); this was selected as a long-term monitoring site. This site is located near the Oguri-gawa River where it just joins the Tama-gawa River. The colony $(250 \mathrm{~m}$ along the major axis, $80 \mathrm{~m}$ along the minor axis) was located in a small area of woods surrounded by houses in a newly built town. The woods mainly consisted of Quercus serrata and Q. acutissima and some Pinus densiflora. In 2000, however, the colony abandoned this site and relocated to a new breeding site on a hilltop in Tama Zoological Park $\left(35^{\circ} 38^{\prime} \mathrm{N}, 139^{\circ} 24^{\prime} \mathrm{E}\right)$, located about $5 \mathrm{~km}$ west of Renkoji along the Tama-gawa River. In the zoo, woods are patchily distributed, and the Grey Herons use an area $(290 \mathrm{~m}$ along the major axis, $220 \mathrm{~m}$ along the minor axis) consisting of Quercus serrata, Q. acutissima, Carpinus tschonoskii, Prunus jamasakura, and Pinus densiflora.
2.2. Observations. After colony establishment was first noted at Renkoji in mid-1996 [28], the herons were observed systematically beginning from the next year (1997) using binoculars $(\times 10)$ and a spotting scope $(\times 20-60$; TSN-1, Kowa, Nagoya). Herons that stayed in their nests were identified to species. I monitored the typical behavior of breeding individuals (nest building, incubation, or guarding) and the number and body size of chicks (small, medium, or large), if present, at intervals of 3-7 days in 1997 and every 7-10 days in 1998-2000. In 2000, the 49 breeding pairs of this colony had disappeared by late April, and no herons were observed afterwards. However, 14 pairs were observed making nests since late March in 2000. Therefore, I continued to census this consecutive colony at intervals of 7-10 days in 2001, but at intervals of 3-4 days in 2002-2008 and 7 days in 2009-2011. From the census data, the breeding and nestling feeding durations of each nest were calculated as the period from the day that nest-building behavior was first recorded until fledging was completed (all fledglings disappeared in the nest) and the period from ending incubation (judged from continuous standing of parents) to complete fledging, respectively. If predation occurred in the field, the predators were identified and recorded.

To examine the effects of winter temperature on population fluctuations and the timing of breeding, air temperatures were used from public data recorded by the automated meteorological data acquisition system of the Japan Meteorological Agency at Fuchu, Tokyo $\left(35^{\circ} 41^{\prime} \mathrm{N}, 139^{\circ} 29^{\prime} \mathrm{E}\right)$, located $8.4 \mathrm{~km}$ northeast from Tama Zoological Park. The minimum value among the mean 10-day temperatures recorded from December 1 to January 31 was used as the coldness value starting the breeding season in each year.

Some unintended effects of observations on breeding heron behavior have been identified [29, 30], particularly researcher visits to colonies during nest building and early incubation, leading to abandonment of nests [31]. Artificial effects on heron behavior may be negligible in this study, because census observations were made carefully and far from the nests to avoid disturbing the herons, and because the nests were so high in the trees that any eggs in the nests were not examined.

\section{Results}

In 2001 and 2002, eight and two pairs of Black-Crowned Night Herons (Nycticorax nycticorax) were found, respectively, in the Tama Zoological Park Grey Heron colony. The park staff also reported that this colony included at least 13 nests of Black-Crowned Night Herons in 2000 [32]. In all other years, only Grey Herons nested within the colony. The number of nests used by the pairs increased annually after colony establishment at Renkoji but tended to become saturated after about 10 years (Figure 1). The mean duration of breeding by each pair ranged from 99.1 to 129.0 days, and the mean duration of nestling feeding ranged from 53.6 to 67.8 days (Table 1). The proportion of successful nests that fledged was $62.6 \%-85.3 \%$, excluding all that were unsuccessful by the abandonment of the site in 2000 (Table 1). The maximum 


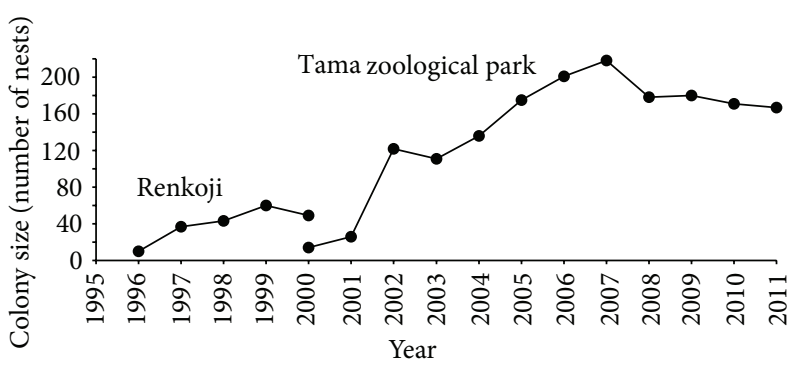

Figure 1: Yearly changes in the number of nests in the Renkoji and Tama Zoological Park colonies. In 2000, the Renkoji site was abandoned, and a new colony was established at the Tama Zoological Park close to Renkoji.

number of fledglings was four, and the mean number of fledglings per successful nests ranged from 1.8 to 3.1 (Table 1). The date that the first pair(s) began to breed in the colony differed from year to year, ranging from January 4 to March 3 (Table 1). The mean start date of breeding by pairs also differed yearly, and the coefficient of variation $(\mathrm{CV})$ in the start date of colony members ranged from $20.8 \%$ to $55.6 \%$ (Table 1).

For the effect of colony size on breeding parameters (Figure 2), breeding duration increased with colony size, but nestling feeding duration was not correlated with colony size. Colony size did not affect the proportion of successful nests, but the mean number of fledglings per successful nest decreased with colony size. As the colony size increased, the date of the first breeding became earlier, and variation in the timing of the onset of breeding by individual pairs was higher.

In the relationships between the date that each pair began breeding and the duration of breeding or nestling feeding (Figure 3, Table 2), the breeding duration was usually longer in early breeders than in late breeders. However, the nestling feeding duration did not differ greatly between earlier and later breeding pairs, suggesting that the duration until nestling feeding was elongated in earlier breeders. In most years, the number of fledglings decreased as the date of the onset of breeding was delayed (Figure 4, Table 2).

Air temperatures were warmer $\left(4.0-5.4^{\circ} \mathrm{C}\right.$ in mean temperature for a period of 10 days of the coldest period) at the beginning of breeding in 2000, 2002, 2004, 2007, and 2009 , but were colder $\left(1.9-2.9^{\circ} \mathrm{C}\right)$ in $1998,2001,2003,2006$, and 2011, compared to temperatures in 1997, 1999, 2005, 2008 , and $2010\left(3.6-3.9^{\circ} \mathrm{C}\right)$. However, winter temperature was unlikely to explain yearly changes in colony size (Figure 1). Moreover, the two groups of warmer and colder years did not significantly differ in the date of the onset of breeding of the colony (Student's $t$-test; $t=0.70, \mathrm{df}=8, P=0.70$ ), the CV in individual breeding date $(t=1.14, \mathrm{df}=7, P=0.29)$, or other reproductive traits (breeding duration: $t=0.04, \mathrm{df}=7$, $P=0.97$; nestling feeding duration: $t=0.22, \mathrm{df}=7, P=0.83$; number of successful nests: $t=0.51, \mathrm{df}=7, P=0.63$; number of fledglings per successful nest: $t=0.43, \mathrm{df}=7, P=0.68$ ).

Predation rarely occurred during the censuses. The observed predators of eggs and chicks were the Japanese rat snake Elaphe climacophora $(N=1)$ and the jungle crow Corvus macrorhynchos $(N=14)$.

\section{Discussion}

4.1. Density Dependence. The Renkoji site was abandoned 4 years after establishment and the colony relocated to a new site in Tama Zoological Park close to Renkoji along the Tama-gawa River. Higher rates of nest mortality lead to significant decreases in colony size, and breeding colony distributions often shift in association with these reductions in colony size [33,34]. For example, a colony of Great Blue Herons at Pender Harbour, British Columbia, abandoned their site after 2 years of high predation by Ravens (Corvus corax), Bald Eagles (Haliaeetus leucocephalus), and probably raccoons (Procyon lotor) $[8,35]$. Heavy predation may thus force colony abandonment by herons. In the study population, however, predation was rarely observed. The snake Elaphe climacophora and the crow Corvus macrorhynchos were the only predators of eggs and chicks recorded in the present study. Colony nesting of birds sometimes damages vegetation, mainly by altering soil nutrient concentration [36, 37]. Vegetation degradation may cause shifting the colony site [38]. In this study, however, obvious change in vegetation occurred for 16 years even at the central part of colonies. Thus, the cause of the relocation of the colony remains unknown.

In the present study, the colony size increased yearly after establishment and later became saturated (Figure 1), similar to the patterns reported for Grey Herons in two Spanish colonies [39, 40]. Density-dependent processes may be important factors causing such a demographic pattern. The mean clutch size and fledglings per successful nest have been reported to be 3.3-4.2 and 2.1-3.9, respectively, for Grey Herons [41]. In the present study, fledglings per successful nest ranged from 1.8 to 3.1 with a mean of $2.2(\mathrm{SD}=0.3$, $N=14$ ), but the fledgling number decreased with colony size (Figure 2(d)), suggesting a density-dependent response. In a study on White Herons in New Zealand, the mean number of fledglings per nest also decreased as the number of nests in the colony increased [3]. In the present study, the timing of breeding may have also been density dependent, because the breeding duration became longer (Figure 2(a)), the reproductive season occurred earlier (Figure 2(e)), and variation among individuals increased (Figure 2(f)) as the colony size increased. The tendency to delay the initial egglaying date when colony size is large has also been reported for Purple Herons in southern France [4].

The mechanisms of density dependence in demography involve both extrinsic (food) and intrinsic (social behavior) factors [42]. Increased feeding visits by parents (i.e., higher food availability to chicks) decrease the chick mortality of Grey Herons [9]. The nestling feeding duration of Grey Herons, particularly when feeding small chicks, becomes longer when the frequency of returns to the nest decreases, likely because of less food availability at hunting sites [43]. In a field experiment using food supplements, Great Blue Herons showed increased clutch size and fledging success but no difference in the seasonal timing of nesting [44]. Thus, 


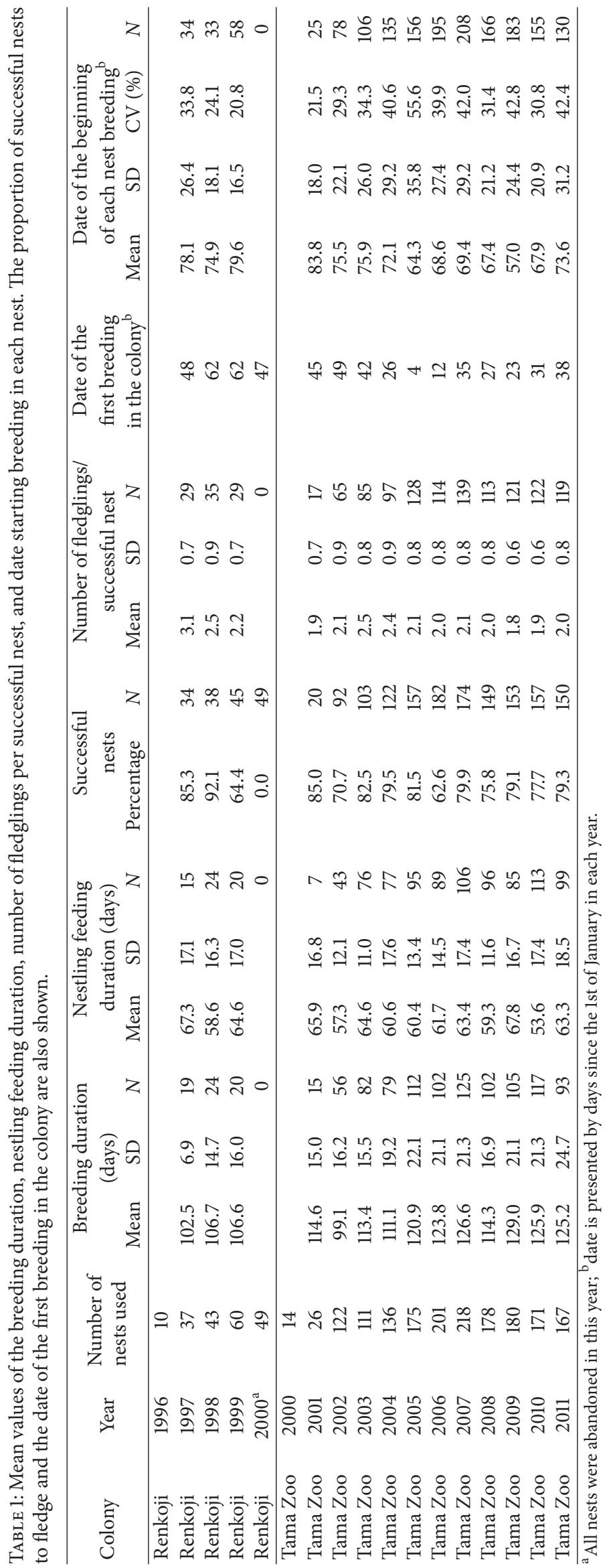




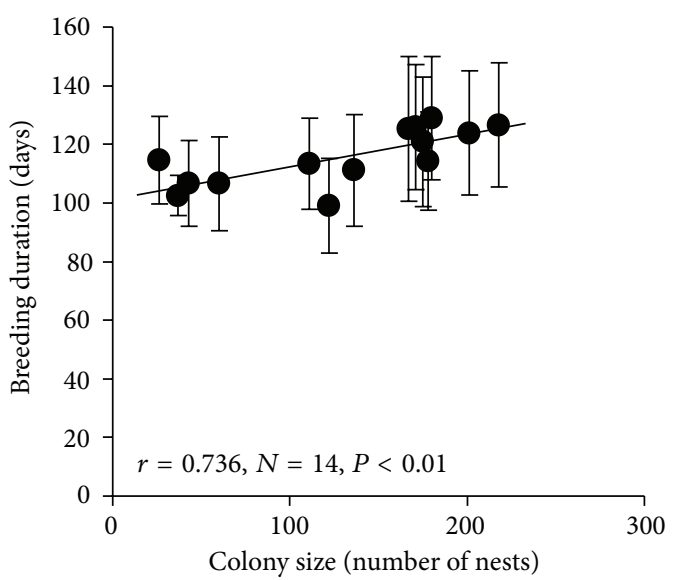

(a)

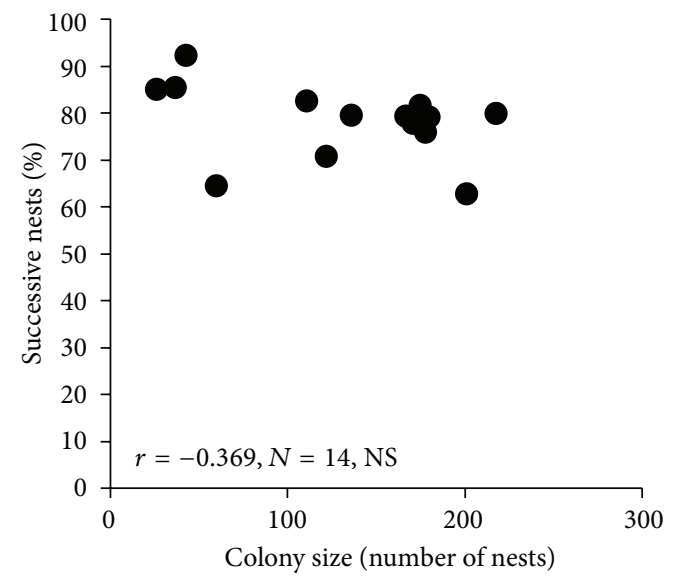

(c)

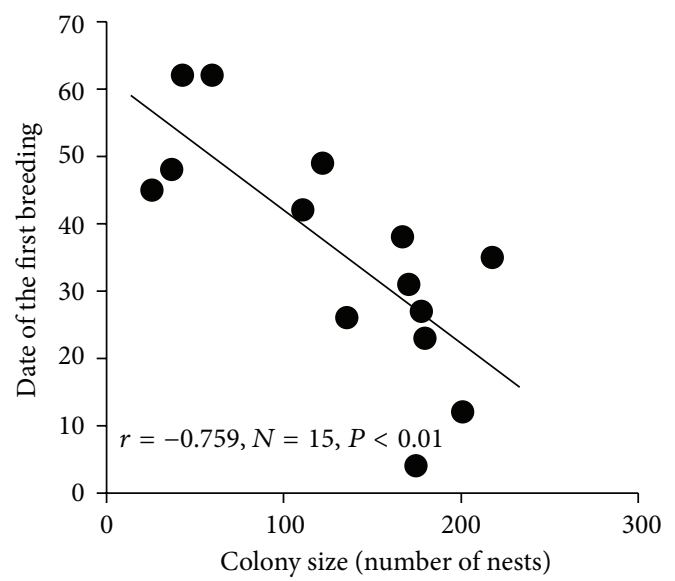

(e)

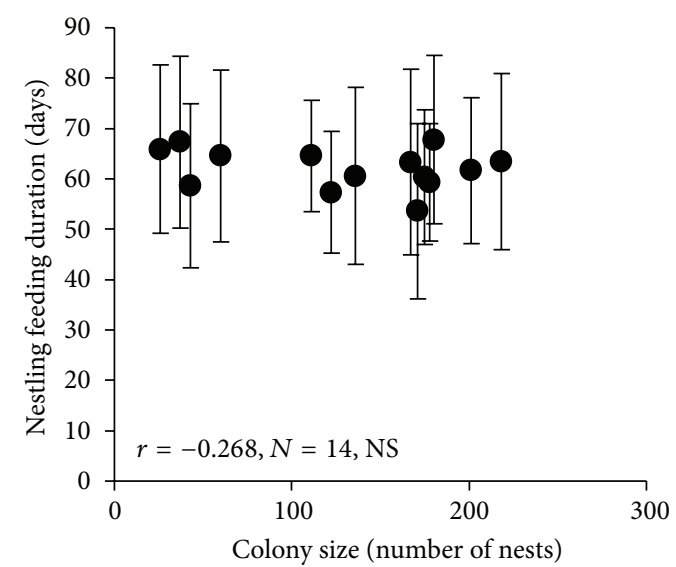

(b)

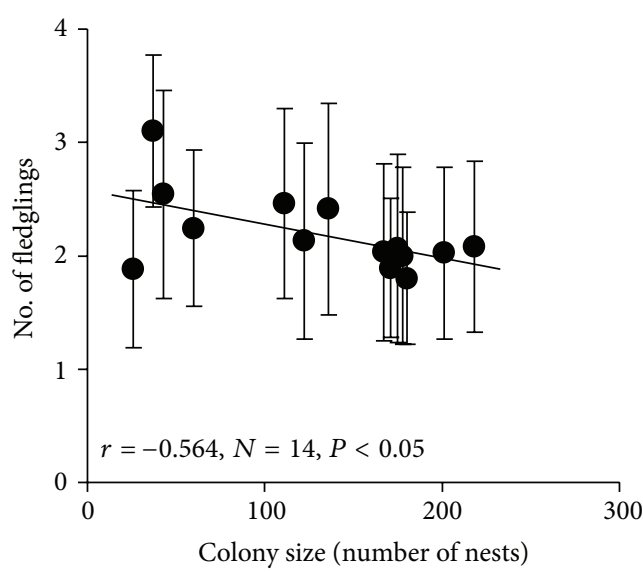

(d)

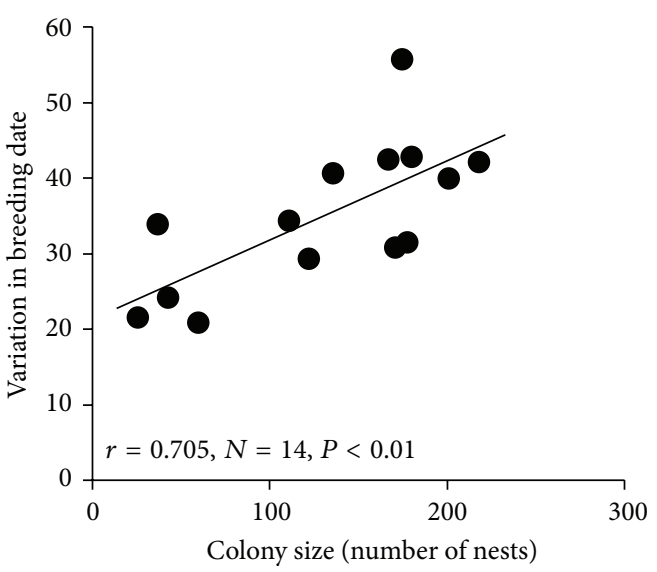

(f)

FIGURE 2: Relationships between colony size and (a) breeding duration, (b) nestling feeding duration, (c) proportion of successfully fledged nests, (d) number of fledglings per successful nest, (e) date of the first breeding in the colony, and (f) coefficient of variation in the date of the onset of breeding by individuals. Bars indicate \pm SD. 

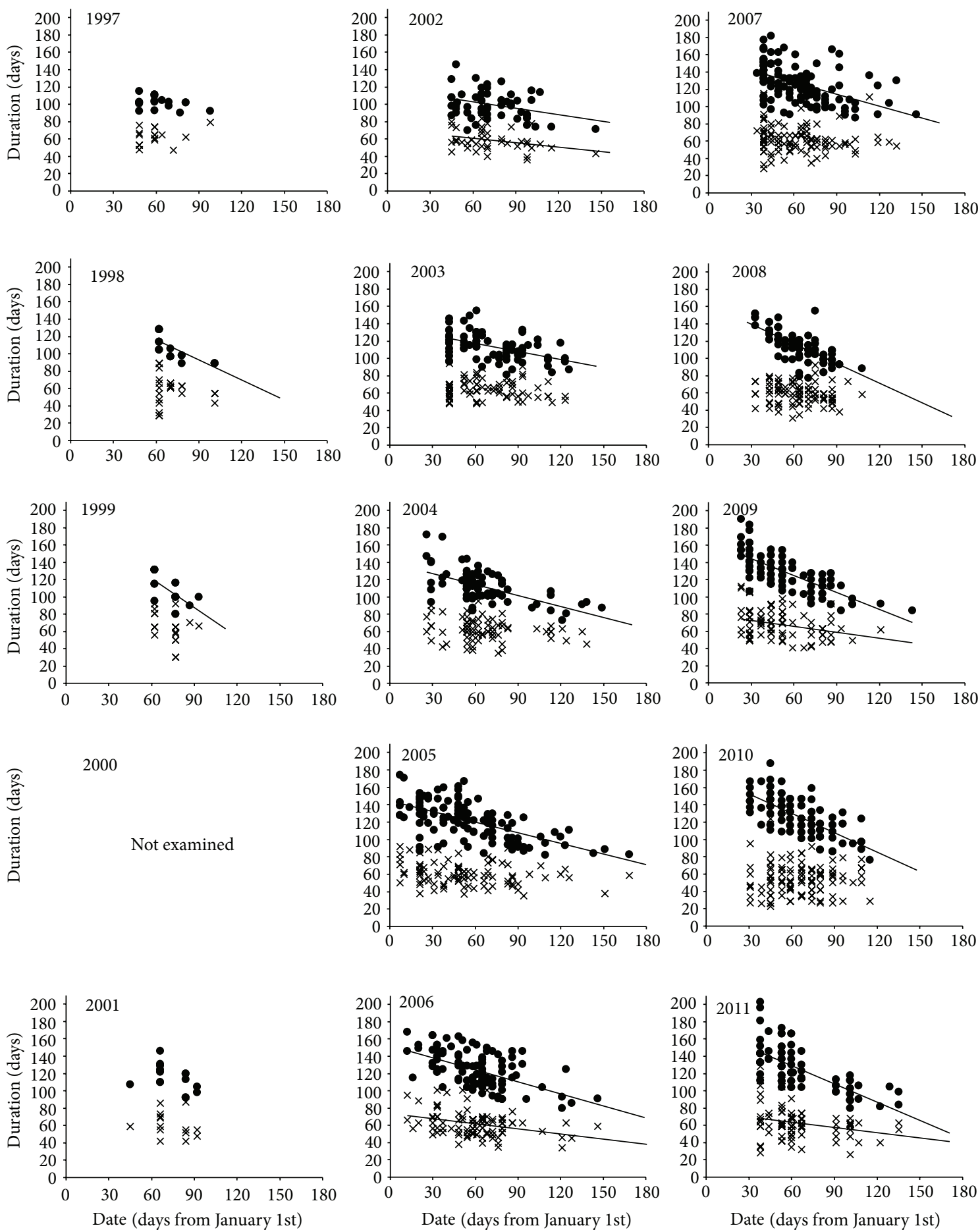

FIGURE 3: Breeding $(\bullet)$ or nestling feeding $(\times)$ durations of each pair of Grey Herons in relation to the date of the beginning of breeding in each year. Regression lines are shown when the correlation coefficients are statistically significant (see Table 2).

competition for limited food is a possible source of density dependence. However, the effect of food availability on colony size is usually difficult to detect, because food searching areas used by colony members cannot be tracked completely. In Portugal, Cattle Egret (Bubulcus ibis) colonies reportedly depend on the areas of dry pasture and crops within a $5 \mathrm{~km}$ radius of the colony center, and Little Egrets (Egretta garzetta) depend on the presence of freshwater and saltwater habitats within a $5 \mathrm{~km}$ area [45]. Estimating the amount of available food over such a wide range of habitat would be difficult.

Social factors involved in density dependence may be direct behavioral interference among colony members. In herons and egrets, intraspecific interactions may be critical in courtship and nesting $[1,46]$. In the present study, 

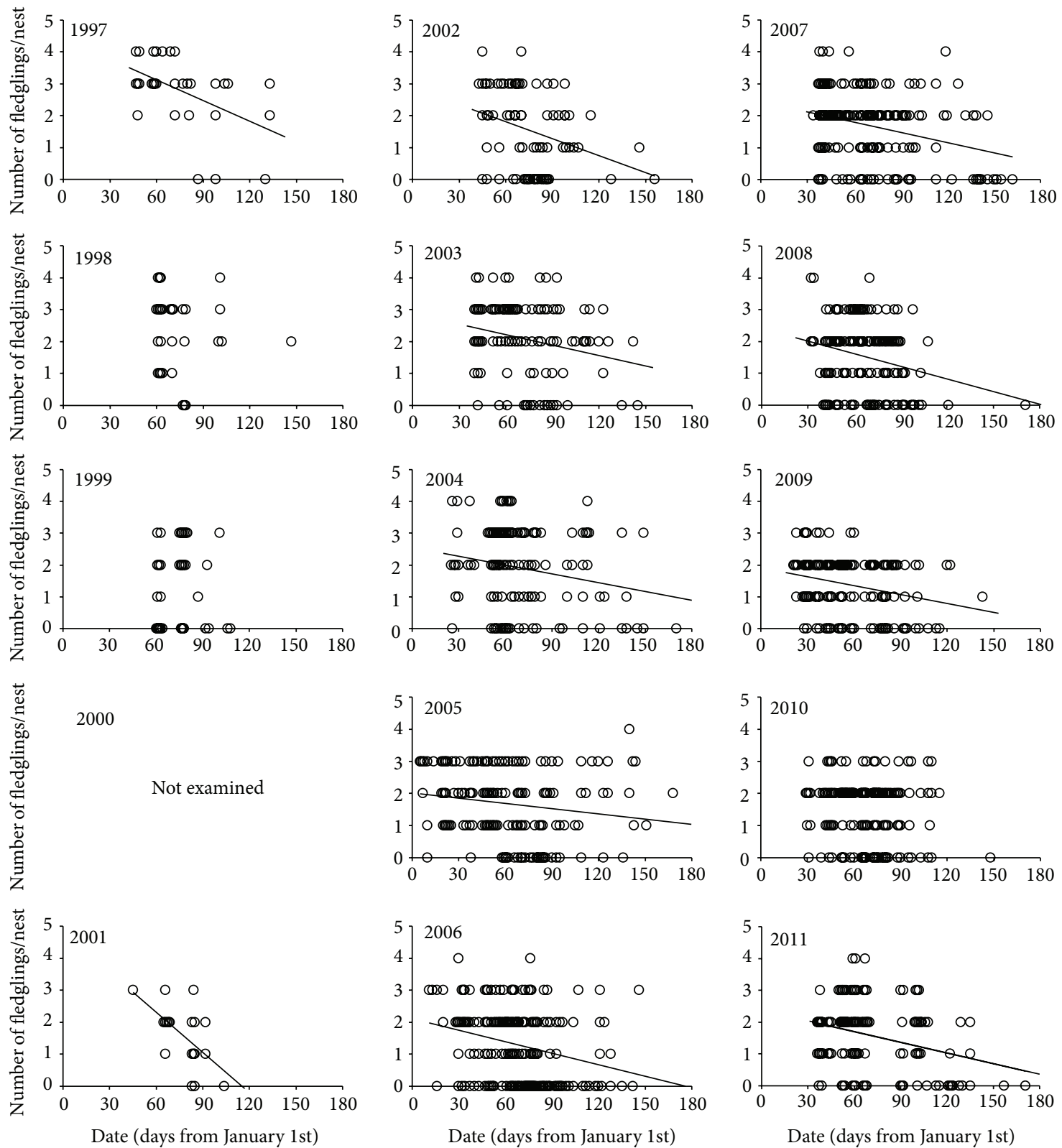

FIGURE 4: Number of fledglings per nest in relation to the date of the beginning of breeding in each nest. Regression lines are shown when the correlation coefficients are statistically significant (see Table 2).

earlier breeders took a longer period of time until nestling feeding (i.e., the period from nest building to completed egg incubation) than later breeders (Figure 3). The prolonged prenestling feeding duration may have been caused by unstable states of colony members at the beginning of the breeding season. During this period, interference is expected to be frequent and intense, because the colony includes many birds that have arrived and joined the colony that year. To confirm this interference hypothesis, quantitative data examining the relationship between interference frequency and colony size are needed.

Despite these possible intense interactions in the early breeding season, the number of fledged chicks was greater for earlier breeders than for later breeders (Figure 4). A similar decline in the number of fledglings with a later date of the onset of breeding was observed for Grey Herons in Poland, although it was not observed every year [19]. Brood size is often larger in earlier breeders within a reproductive season in birds [47], as observed in Grey Herons [7, 48, 49] and other heron and egret species [50-52]. On the other hand, mean brood size increases with the age of parents $[53,54]$. Older individuals may be more successful in acquiring nest sites of good quality and have more experience in parental care $[54,55]$. In the present study, these age effects could not be assessed. In the future, to discriminate the effects of the age of parents and the timing of breeding on reproductive success, 
TABLE 2: Correlation coefficients between the date of starting breeding and the breeding duration, the nestling feeding duration, or the number of fledglings in each nest.

\begin{tabular}{|c|c|c|c|c|c|c|c|c|c|c|}
\hline \multirow{2}{*}{ Colony } & \multirow{2}{*}{ Year } & \multicolumn{3}{|c|}{ Breeding duration } & \multicolumn{3}{|c|}{ Nestling feeding duration } & \multicolumn{3}{|c|}{ Number of fledglings } \\
\hline & & $r$ & $N$ & $P$ & $r$ & $N$ & $P$ & $r$ & $N$ & $P$ \\
\hline Renkoji & 1996 & & & & & & & & & \\
\hline Renkoji & 1997 & -0.376 & 19 & NS & 0.285 & 16 & NS & -0.495 & 30 & $* *$ \\
\hline Renkoji & 1998 & -0.751 & 24 & $* * *$ & -0.135 & 24 & NS & -0.048 & 30 & NS \\
\hline Renkoji & 1999 & -0.647 & 20 & $* *$ & -0.350 & 19 & NS & -0.013 & 37 & NS \\
\hline Renkoji & 2000 & & & & & & & & & \\
\hline Tama Zoo & 2000 & & & & & & & & & \\
\hline Tama Zoo & 2001 & -0.422 & 15 & NS & -0.233 & 14 & NS & -0.591 & 19 & $* *$ \\
\hline Tama Zoo & 2002 & -0.329 & 54 & * & -0.323 & 40 & $*$ & -0.327 & 78 & $* *$ \\
\hline Tama Zoo & 2003 & -0.475 & 79 & $* * *$ & -0.121 & 74 & NS & -0.233 & 100 & * \\
\hline Tama Zoo & 2004 & -0.589 & 78 & $* * *$ & -0.213 & 76 & NS & -0.218 & 117 & * \\
\hline Tama Zoo & 2005 & -0.614 & 111 & $* * *$ & -0.203 & 94 & NS & -0.178 & 150 & * \\
\hline Tama Zoo & 2006 & -0.548 & 102 & $* * *$ & -0.342 & 89 & $* *$ & -0.287 & 180 & $* *$ \\
\hline Tama Zoo & 2007 & -0.500 & 125 & $* * *$ & -0.118 & 106 & NS & -0.311 & 170 & $* * *$ \\
\hline Tama Zoo & 2008 & -0.743 & 101 & $* * *$ & -0.136 & 95 & NS & -0.252 & 143 & $* *$ \\
\hline Tama Zoo & 2009 & -0.751 & 105 & $* * *$ & -0.311 & 84 & $* *$ & -0.267 & 137 & $* *$ \\
\hline Tama Zoo & 2010 & -0.709 & 117 & $* * *$ & 0.032 & 110 & NS & -0.110 & 150 & NS \\
\hline Tama Zoo & 2011 & -0.702 & 93 & $* * *$ & -0.255 & 87 & $*$ & -0.307 & 120 & * \\
\hline
\end{tabular}

NS, $P>0.05 ;{ }^{*} P<0.05 ;{ }^{* *} P<0.01 ;{ }^{* * *} P<0.001$.

the age of the Grey Herons must be determined by marking individuals.

4.2. Density Independence. Unpredictable factors can explain reduced breeding success and increased mortality in some regions without invoking density-dependent mechanisms [5, $10,11]$. For example, in a study conducted in the Yucatan Peninsula, most herons and egrets failed to reproduce because of food shortages caused by exceptionally heavy rains and flooding of their lowland habitats [10].

Another well-known density-independent process that can reduce population size in herons and egrets is unpredicted severely low temperatures in winter. The Grey Heron population in England and Wales usually numbers 45004800 , but after severe winters, it decreases to around 3000 [12]. In particular, winter (January to March) temperature strongly affects the survival rate of first-year Grey Herons in England, as estimated by the annual recovery of banded nestlings from 1955 to 1974 [13]. In those studies, in a year when temperatures reached about $1^{\circ} \mathrm{C}$, few young birds survived, whereas during years with winter temperatures above $6^{\circ} \mathrm{C}$, more than half survived. A large number of Grey Herons also died during a cold spell in January and February 1976 in The Netherlands [14]. In northwest Italy, Grey Herons increased following an increase in winter temperature [15]. In France, however, the survival of yearling Little Egrets did not appear to be affected by winter severity [56].

In the present 16-year study, winter temperature was unlikely to explain yearly variation in reproductive parameters. In Poland, Grey Herons in inland colonies begin to breed later than those in coastal colonies, because spring air temperatures are lower and ice cover is present on feeding sites for a longer duration in inland locations [19]. Thus, the accessibility of feeding sites (lack of ice cover) in spring is an important factor affecting the onset of breeding. However, in suburban Tokyo, winter temperatures are relatively mild and rarely fall below $0^{\circ} \mathrm{C}$. Therefore, annual differences in the onset of breeding are not likely related to temperature, as in the case of Little Egrets in France [56].

\section{Acknowledgments}

The author thanks Fumio Hayashi, Tamotsu Kusano, and Tadashi Suzuki for their help with many aspects of this study and particularly F. Hayashi for the improvement of an earlier version of this paper. He also thanks Kazuyoshi Ito, Etsuo Narushima, Tomoko Yabe, Yasumasa Tomita, and Heizo Sugita for allowing him to study at Tama Zoological Park and Fumio Nakamura for his help in initiating a study there.

\section{References}

[1] J. A. Kushlan and J. A. Hancock, The Herons, Oxford University Press, New York, NY, USA, 2005.

[2] I. Newton, Population Limitation in Birds, Academic Press, London, UK, 1998.

[3] C. Miller, "Long-term monitoring of a breeding colony of white herons (Egretta alba) on the Waitangiroto river, South Westland, New Zealand," Notornis, vol. 48, no. 3, pp. 157-163, 2001.

[4] C. Barbraud, M. Lepley, V. Lemoine, and H. Hafner, "Recent changes in the diet and breeding parameters of the Purple Heron Ardea purpurea in Southern France," Bird Study, vol. 48, no. 3, pp. 308-316, 2001. 
[5] R. W. Butler, "Population regulation of wading ciconiiform birds," Colonial Waterbirds, vol. 17, no. 2, pp. 189-199, 1994.

[6] R. Lande, S. Engen, and B. E. Sæther, "Estimating density dependence in time-series of age-structured populations," Philosophical Transactions of the Royal Society B, vol. 357, no. 1425, pp. 1179-1184, 2002.

[7] J. van Vessem and D. Draulans, "The adaptive significance of colonial breeding in the Grey Heron Ardea cinerea: inter- and intra-colony variability in breeding success," Ornis Scandinavica, vol. 17, no. 4, pp. 356-362, 1986.

[8] R. W. Butler, P. E. Whitehead, A. M. Breault, and I. E. Moul, "Colony effects on fledging success of Great Blue Herons (Ardea herodias) in British Columbia," Colonial Waterbirds, vol. 18, no. 2, pp. 159-165, 1995.

[9] D. Jakubas, "Factors affecting the breeding success of the Grey Heron (Ardea cinerea) in Northern Poland," Journal of Ornithology, vol. 146, no. 1, pp. 27-33, 2005.

[10] A. Lopez-Ornat and C. Ramo, "Colonial waterbird populations in the Sian Ka'an Biosphere Reserve (Quintana Roo, Mexico)," The Wilson Bulletin, vol. 104, no. 3, pp. 501-515, 1992.

[11] E. M. Kirsch, B. Ickes, and D. A. Olsen, "Assessing habitat use by breeding Great Blue Herons (Ardea herodias) on the upper Mississippi River, USA," Waterbirds, vol. 31, no. 2, pp. 252-267, 2008.

[12] J. Stafford, “The heron population of England and Wales, 19281970," Bird Study, vol. 18, no. 4, pp. 218-221, 1971.

[13] P. M. North and B. J. T. Morgan, "Modelling heron survival using weather data," Biometrics, vol. 35, no. 3, pp. 667-681, 1979.

[14] E. J. van der Molen, A. A. Blok, and G. J. de Graaf, "Winter starvation and mercury intoxication in Grey Herons (Ardea cinerea) in The Netherlands," Ardea, vol. 70, no. 2, pp. 173-184, 1982.

[15] M. Fasola, D. Rubolini, E. Merli, E. Boncompagni, and U. Bressan, "Long-term trends of heron and egret populations in Italy, and the effects of climate, human-induced mortality, and habitat on population dynamics," Population Ecology, vol. 52, no. 1, pp. 59-72, 2010.

[16] J. Walmsley, "The development of a breeding population of Grey Herons (Ardea cinerea) in the Camargue," La Terre et la Vie, vol. 29, pp. 89-99, 1975.

[17] L. Marion, "Territorial feeding and colonial breeding are not mutually exclusive: the case of the Grey Heron (Ardea cinerea)," Journal of Animal Ecology, vol. 58, no. 2, pp. 693-710, 1989.

[18] F. Campos and M. Fernández-Cruz, "The breeding biology of the Grey Heron (Ardea cinerea) in the Duero river basin in Spain," Colonial Waterbirds, vol. 14, pp. 57-60, 1991.

[19] D. Jakubas, "The influence of climate conditions on breeding phenology of the Grey Heron Ardea cinerea L. in Northern Poland," Polish Journal of Ecology, vol. 59, no. 1, pp. 179-192, 2011.

[20] J. A. Kushlan and H. Hafner, Heron Conservation, Academic Press, London, UK, 2000.

[21] H. Hafner, R. E. Bennetts, and Y. Kayser, "Changes in clutch size, brood size and numbers of nesting Squacco Herons Ardeola ralloides over a 32-year period in the Camargue, Southern France," Ibis, vol. 143, no. 1, pp. 11-16, 2001.

[22] J. P. Kelly, K. Etienne, C. Strong, M. McCaustland, and M. L. Parkes, "Status, trends, and implications for the conservation of heron and egret nesting colonies in the San Francisco Bay area," Waterbirds, vol. 30, no. 4, pp. 455-478, 2007.

[23] A. Ismail and F. Rahman, "Population dynamics of colonial waterbirds in upper Bisa, Putrajaya Wetlands, Malaysia," Acta Biologica Malaysiana, vol. 1, no. 1, pp. 36-40, 2012.
[24] R. E. Bennetts, M. Fasola, H. Hafner, and Y. Kayser, "Influence of environmental and density-dependent factors on reproduction of Little Egrets," The Auk, vol. 117, no. 3, pp. 634-639, 2000.

[25] L. Dami, R. E. Bennetts, and H. Hafner, "Do Cattle Egrets exclude Little Egrets from settling at higher quality sites within mixed-species colonies?" Waterbirds, vol. 29, no. 2, pp. 154-162, 2006.

[26] Committee for Check-list of Japanese Birds, Check-List of Japanese Birds, Ornithological Society of Japan, Tokyo, Japan, 6th edition, 2000.

[27] Y. Sawara, N. Azuma, K. Hino, K. Fukui, G. Demachi, and M. Sakuyama, "Feeding activity of the Grey Heron Ardea cinerea in tidal and non-tidal environments," Japanese Journal of Ornithology, vol. 39, no. 2, pp. 45-52, 1990.

[28] T. Shirai, "Breeding biology of Grey Herons Ardea cinerea in the Tama River," Strix, vol. 17, pp. 85-91, 1999 (Japanese).

[29] D. K. Goering and R. Cherry, "Nestling mortality in a Texas heronry," The Wilson Bulletin, vol. 83, no. 3, pp. 303-305, 1971.

[30] P. C. Frederick and M. W. Collopy, "Researcher disturbance in colonies of wading birds: effects of frequency of visit and eggmarking on reproductive parameters," Colonial Waterbirds, vol. 12, no. 2, pp. 152-157, 1989.

[31] J. Tremblay and L. N. Ellison, "Effects of human disturbance on breeding of black-crowned night herons," The Auk, vol. 96, no. 2, pp. 364-369, 1979.

[32] H. Sugita, "Wild Grey Herons nesting in the zoo. The bird watching group of Tama Zoo," Animals and Zoos, vol. 53, no. 9, p. 21, 2001 (Japanese).

[33] T. Boulinier, "On breeding performance, colony growth and habitat selection in Buff-Necked Ibis," Condor, vol. 98, no. 2, pp. 440-441, 1996.

[34] E. Danchin, T. Boulinier, and M. Massot, "Conspecific reproductive success and breeding habitat selection: implications for the study of coloniality," Ecology, vol. 79, no. 7, pp. 2415-2428, 1998.

[35] K. Simpson, J. N. M. Smith, and J. P. Kelsall, "Correlates and consequences of coloniality in great blue herons," Canadian Journal of Zoology, vol. 65, no. 3, pp. 572-577, 1987.

[36] A. Ishida, "Changes of soil properties in the colonies of the common cormorant, Phalacrocorax carbo," Journal of Forest Research, vol. 1, no. 1, pp. 31-35, 1996.

[37] H. T. Mun, "Effects of colony nesting of Adrea cinerea and Egretta alba modesta on soil properties and herb layer composition in a Pinus densiflora forest," Plant and Soil, vol. 197, no. 1, pp. 55-59, 1997.

[38] K. Ogasawara, K. Abe, and T. Naito, "Ecological study of Grey Heron in Oga Peninsula, Akita Prefecture," Journal of Yamashina Institute for Ornithology, vol. 14, no. 2-3, pp. 232245, 1982.

[39] M. Fernández-Cruz and F. Campos, "The breeding of Grey Herons (Ardea cinerea) in Western Spain: the influence age," Colonial Waterbirds, vol. 16, no. 1, pp. 53-58, 1993.

[40] J. Prosper and H. Hafner, "Breeding aspects of the colonial ardeidae in the Albufera de Valencia, Spain: population changes, phenology, and reproductive success of the three most abundant species," Colonial Waterbirds, vol. 19, no. 1, pp. 98-107, 1996.

[41] J. Kim and T.-H. Koo, "Nest site characteristics and reproductive parameters of Grey Herons Ardea cinerea in Korea," Zoological Studies, vol. 48, pp. 657-664, 2009. 
[42] V. Bretagnolle, F. Mougeot, and J.-C. Thibault, "Density dependence in a recovering osprey population: demographic and behavioural processes," Journal of Animal Ecology, vol. 77, no. 5, pp. 998-1007, 2008.

[43] J. van Vessem and D. Draulans, "Factors affecting the length of the breeding cycle and the frequency of nest attendance by Grey Herons Ardea cinerea," Bird Study, vol. 33, no. 2, pp. 98-104, 1986.

[44] G. V. N. Powell, "Food availability and reproduction by Great White Herons, Ardea herodias: a food addition study," Colonial Waterbirds, vol. 6, pp. 139-147, 1983.

[45] J. C. Farinha and D. Leitão, "The size of heron colonies in Portugal in relation to foraging habitat," Colonial Waterbirds, vol. 19, no. 1, pp. 108-114, 1996.

[46] D. A. McCrimmon Jr., "Nest site characteristics among five species of herons on the North Carolina coast," The Auk, vol. 95, pp. 267-280, 1978.

[47] D. Lack, The Natural Regulation of Animal Numbers, Clarendon Press, Oxford, UK, 1954.

[48] G. Creutz, "Zur Brutbiologie des Graureihers (Ardea cinerea L.) in der Oberlausitz," Beiträge zur Vogelkunde, vol. 21, pp. 161-171, 1975.

[49] J. van Vessem, “Timing of egg-laying, clutch size and breeding success of the Grey Heron, Ardea cinerea, in the North of Belgium," Le Gerfaut, vol. 81, pp. 177-193, 1991.

[50] J. A. Rodgers Jr., "Breeding ecology of the Little Blue Heron (Florida caerulea) on the West coast of Florida, USA," The Condor, vol. 82, no. 2, pp. 164-169, 1980.

[51] J. A. Rodgers Jr., "Breeding chronology and reproductive success of Cattle Egrets and Little Blue Herons on the West coast of Florida, USA," Colonial Waterbirds, vol. 10, no. 1, pp. 38-44, 1987.

[52] G. S. Ranglack, R. A. Angus, and K. R. Marion, "Physical and temporal factors influencing breeding success of Cattle Egrets (Bubulcus ibis) in a West Alabama colony," Colonial Waterbirds, vol. 14, no. 2, pp. 140-149, 1991.

[53] G. S. Baxter, "The influence of synchronous breeding, natal tree position and rainfall on egret nesting success," Colonial Waterbirds, vol. 17, no. 2, pp. 120-129, 1994.

[54] F. Thomas, Y. Kayser, and H. Hafner, "Nestling size rank in the little egret (Egretta garzetta) influences subsequent breeding success of offspring," Behavioral Ecology and Sociobiology, vol. 45, no. 6, pp. 466-470, 1999.

[55] F. Thomas, F. Renaud, T. De Meeus, and F. Cézilly, "Parasites, age and the Hamilton-Zuk hypothesis: inferential fallacy?" Oikos, vol. 74, no. 2, pp. 305-309, 1995.

[56] H. Hafner, Y. Kayser, V. Boy et al., "Local survival, natal dispersal, and recruitment in Little Egrets Egretta garzetta," Journal of Avian Biology, vol. 29, no. 3, pp. 216-227, 1998. 

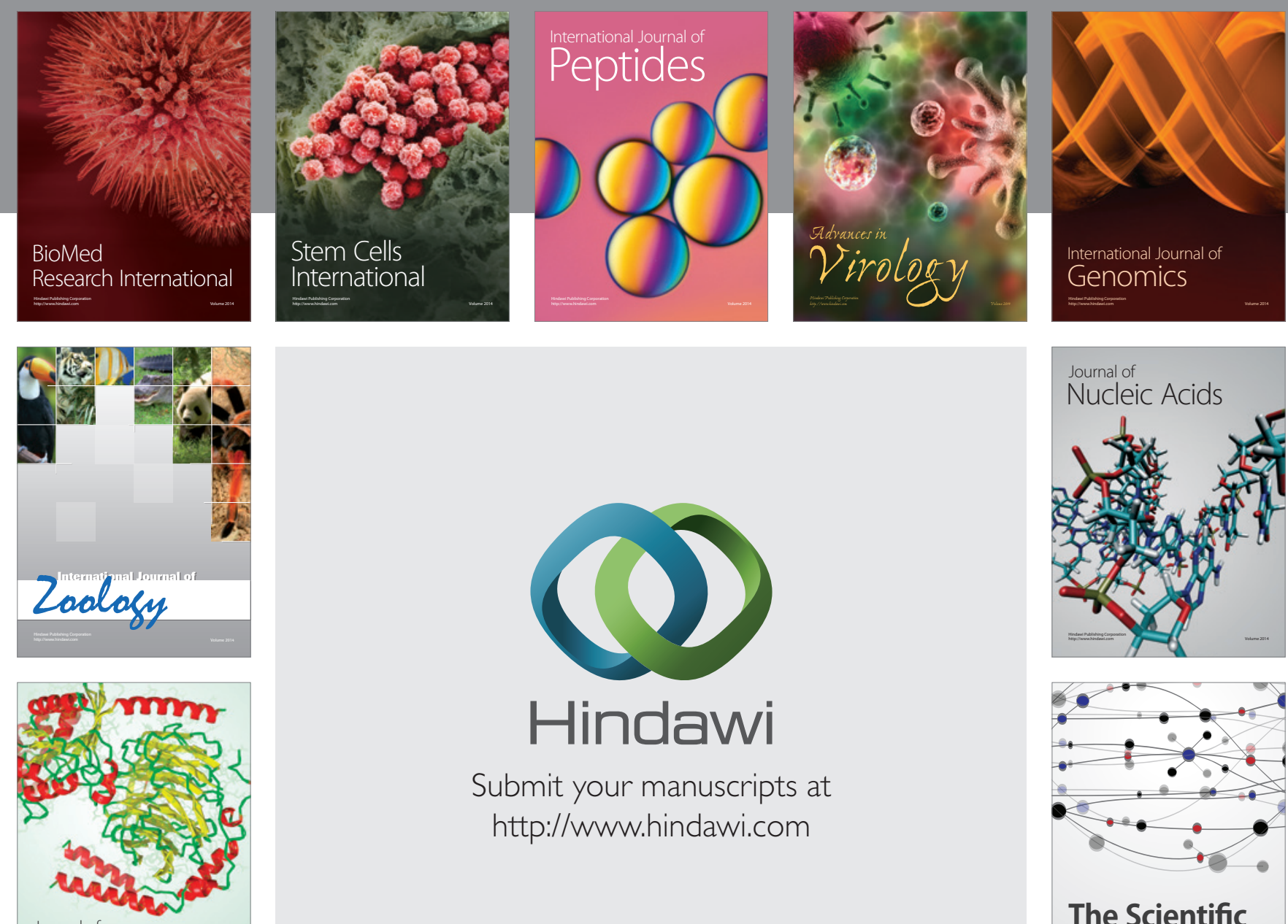

Submit your manuscripts at

http://www.hindawi.com

Journal of
Signal Transduction
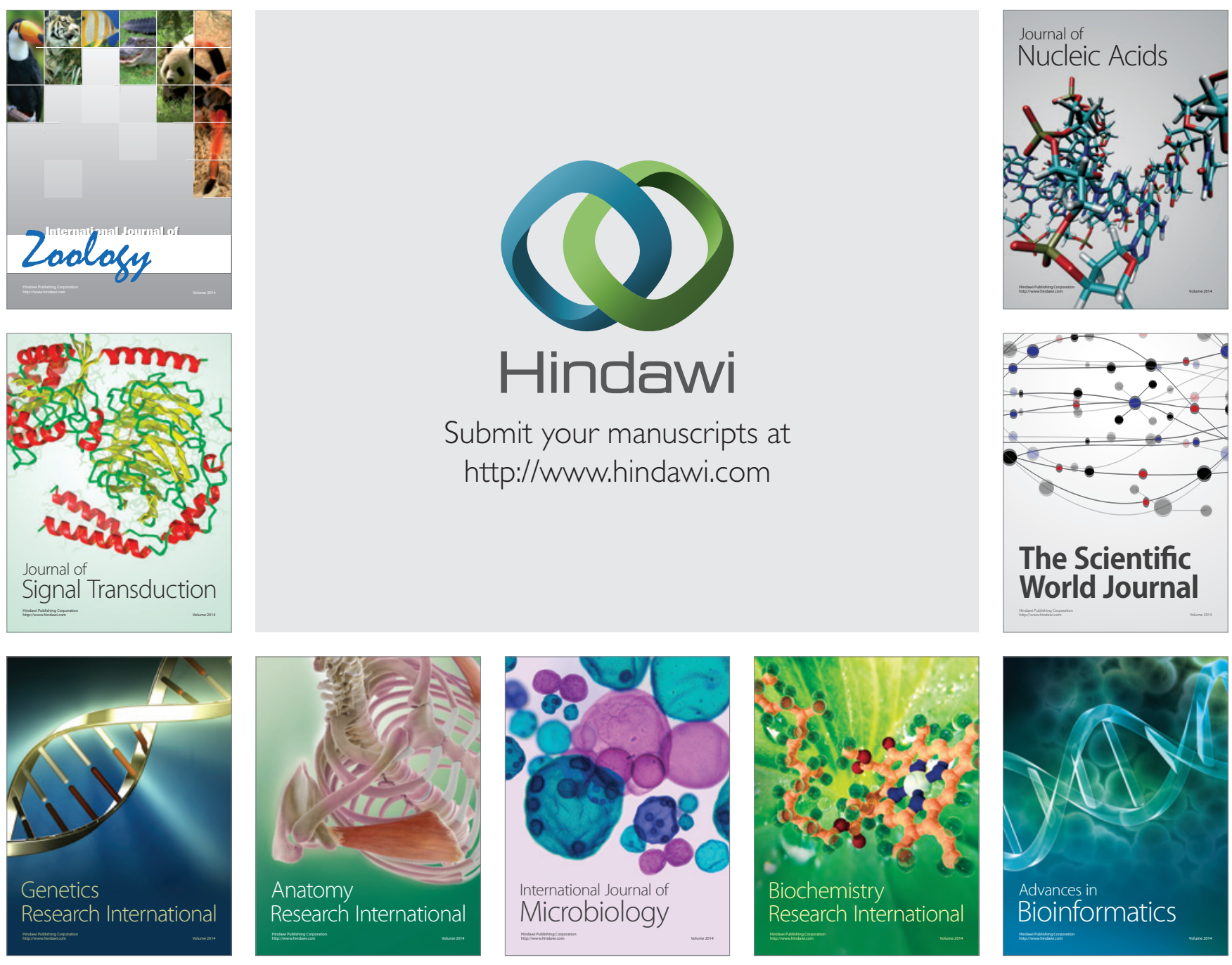

The Scientific World Journal
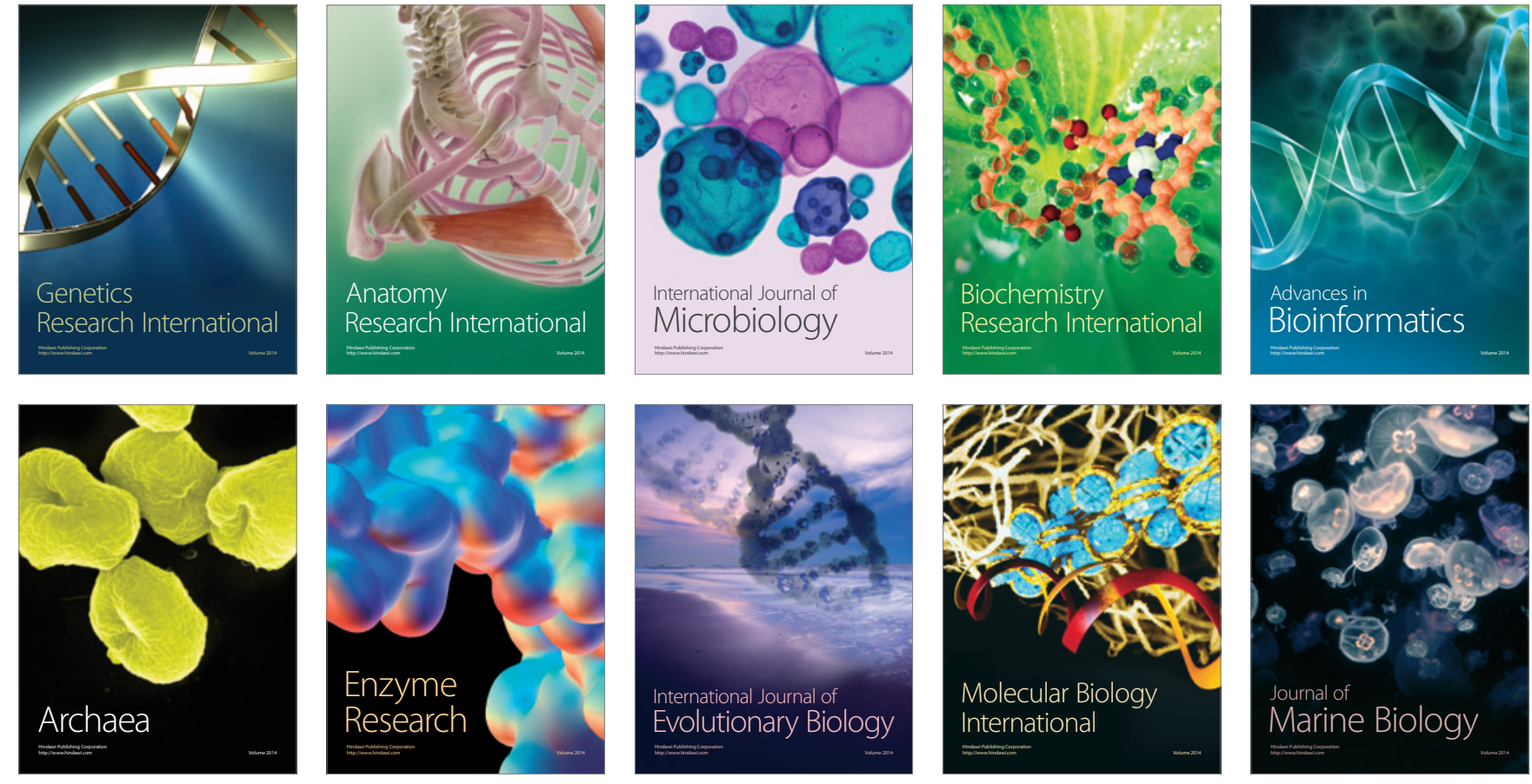